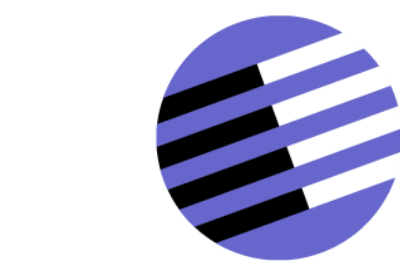

GOVERNANCE AND THE EFFICIENCY

OF ECONOMIC SYSTEMS

G E S Y

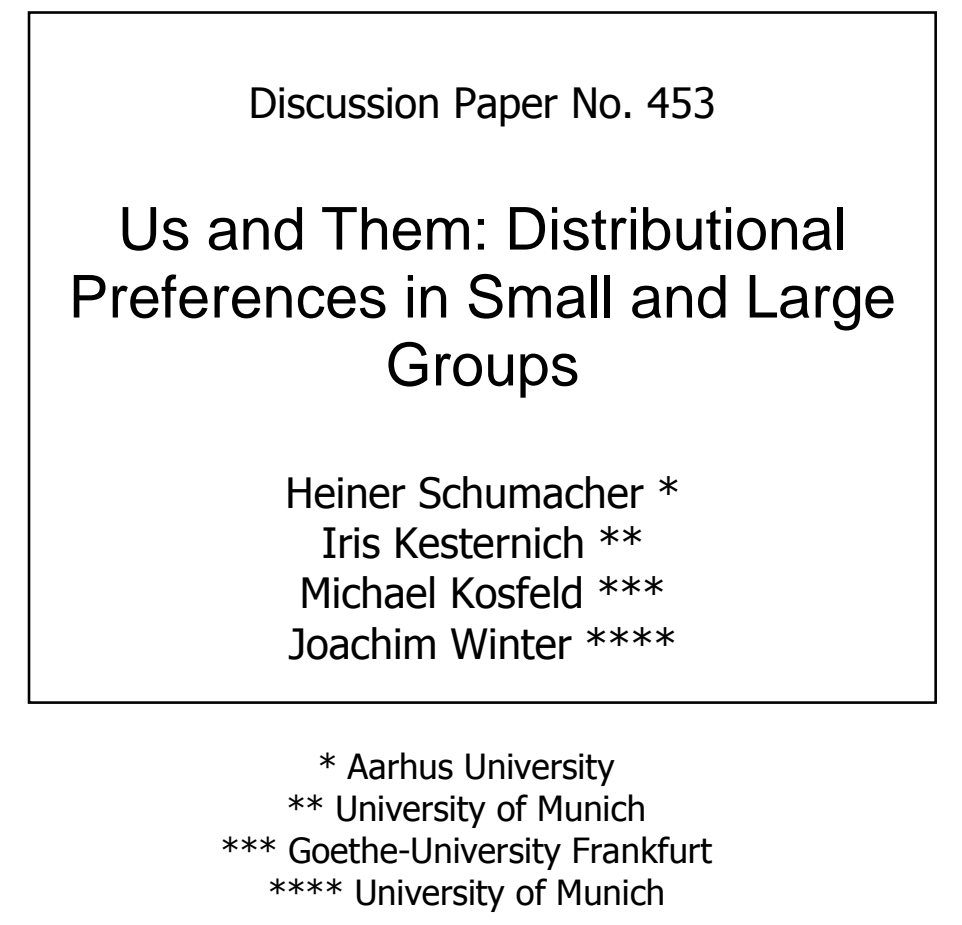

January 17, 2014

Financial support from the Deutsche Forschungsgemeinschaft through SFB/TR 15 is gratefully acknowledged.

Sonderforschungsbereich/Transregio $15 \cdot$ www.sfbtr15.de

Universität Mannheim · Freie Universität Berlin · Humboldt-Universität zu Berlin · Ludwig-Maximilians-Universität München Rheinische Friedrich-Wilhelms-Universität Bonn · Zentrum für Europäische Wirtschaftsforschung Mannheim 


\title{
Us and Them: Distributional Preferences in Small and Large Groups*
}

\author{
Heiner Schumacher ${ }^{\dagger} \quad$ Iris Kesternich ${ }^{\ddagger}$ \\ Michael Kosfeld ${ }^{\S}$ Joachim Winter $₫$ \\ January 17, 2014
}

\begin{abstract}
We analyze distributional preferences in games in which a decider chooses the provision of a good that benefits a receiver and creates costs for a group of payers. The average decider takes into account the welfare of all parties and has concerns for efficiency. However, she attaches similar weights to small and large groups so that she neglects large provision costs that are dispersed among many payers. This holds regardless of whether the decider benefits from the provision or not. A CES utility function which rationalizes average behavior implies altruism in bilateral situations and welfare-damaging actions when costs are dispersed.
\end{abstract}

Keywords: Social Preferences, Distribution Games, Concentrated Benefits and Dispersed Costs

JEL Classification: C91, D63, H00

*This research has profited through financial support by the DFG through MELESSA and SFBTransregio 15. We would like to thank Dirk Engelmann, Guido Friebel, Christina Gravert, Martin Kocher, Henry Mak, Petra Nieken, Maximilian Rueger, Klaus Schmidt, Bertil Tungodden, Joergen Weibull and Nick Zubanov as well as seminar audiences at the CESifo Conferences on Empirical Health Economics and Behavioral Economics, European Economic Association Annual Meeting 2013, Hamburg Center for Health Economics, Harvard Health Care Policy, Indiana University Bloomington, IUPUI, Marburg University, University of Michigan Ann Arbor and Munich University for valuable comments and discussions. We thank Suzan Elshout and the team of programmers at CentERdata Tilburg. We thank Rene Cyranek and the whole MELESSA team for their support. We thank Hendrik Brackmann for excellent research assistance. All remaining errors are our own.

†Corresponding Author. Aarhus University, Department of Economics and Business, Fuglesangs Allé 4, DK-8210 Aarhus V, Denmark, ++45 871 66157, hschumacher@econ.au.dk.

$\ddagger$ University of Munich, iris.kesternich@lrz.uni-muenchen.de.

$\S$ Goethe-University Frankfurt, kosfeld@econ.uni-frankfurt.de.

ฯUniversity of Munich, joachim.winter@lrz.uni-muenchen.de. 


\section{Introduction}

In many domains, an agent's decisions create both benefits for a small, well-defined group and costs that are dispersed among many individuals. When a politician decides about a policy that is favored by a special interest group, she has to weigh the benefits for this group against the costs that the policy creates for the general public. When a physician determines a patient's treatment, she affects not only the patient's well-being, but also the treatment costs that the insurance company (and hence the customers of this company) have to pay. Individuals engaged in illegal behaviors such as corruption or tax evasion typically redistribute income to themselves or their families at the expense of society.

To analyze these behaviors, we need to know how agents trade-off concentrated benefits against dispersed costs. Most theoretical work on special interests, physician behavior, corruption or tax evasion assumes perfectly selfish agents. However, most economists agree that the assumption of pure selfishness is made only for simplicity. There is substantial evidence from the lab and the field that a majority of individuals do not act in completely selfish manner when making decisions that affect the payoff of others.1 One robust finding from the lab is that many individuals take into account the welfare of all parties and have a preference for efficient outcomes (Andreoni and Miller 2002, henceforth AM, Charness and Rabin 2002, Engelmann and Strobel 2004, Fisman et al. 2007). Nevertheless, it is unclear how social preferences are coined in situations where the costs of an action are large, but dispersed among many individuals. Does the average decider then still take into account the welfare of all parties? Or are social concerns restricted to small groups so that dispersed costs are neglected?

We use a controlled experiment to study preferences in distribution games with concentrated benefits and dispersed costs. In each game, a decider chooses the provision of a good which benefits a receiver, but also creates costs for $n$ payers. The decider may or may not benefit from the provision of the good. The treatment variation is the number $n$ of payers; we have $n=1,3,6,40$. We keep the costs per payer constant, so that an increasing number of payers implies increasing costs of provision. If we assume that subjects are partially motivated by the efficiency of the final outcome, the provision of the good should decrease in the number of payers.

The experimental data exhibit the following deviation from this prediction. When we keep the costs per payer constant and increase the number of payers from one to three, we observe, as expected, a significant drop in the provision of the good. However, if

\footnotetext{
${ }^{1}$ See, for example, Fehr and Schmidt (2006) for a review of the evidence from laboratory experiments. Bandiera et al. (2005) provide field evidence for social concerns at the workplace, and DellaVigna et al. (2012) for the role of altruism in charitable giving.
} 
we further increase the number of payers from three to six, and from six to forty, the average provision of the good remains constant. The average decider takes into account the payoff of all parties, but large groups of payers seem to receive just the same weight as small groups. This result holds regardless of whether the decider benefits from the provision of the good or not.

At the same time, two patterns in our data show that the average cares about efficiency. First, in dictator games between the decider and the receiver (the decider pays for the provision of the good, while the payers' payoff is fixed), the average provision of the good is larger if the receiver's marginal benefit exceeds the decider's marginal costs than if it is the other way round. Second, in games with concentrated benefits and dispersed costs, the average provision of the good increases in the receiver's marginal benefit. Note that the opposite would be true if subjects were only motivated by selfishness and maximin preferences.

In order to rationalize these seemingly contradictory results, we develop a parsimonious social preference model. Specifically, we update the CES utility function that AM use to estimate preferences in dictator games. This function captures the main behavioral motives in simple distribution games, i.e., selfishness, efficiency and the welfare of the least-well off individual. The only new element that we introduce is the weight of a single payer's payoff as a function of the number of payers $n$. We can rationalize our results if we assume that this function is strictly increasing, concave and converges to a finite value for $n \rightarrow \infty$. A decider with such a utility function takes the welfare of all parties into account and may increase the provision of the good when the receiver's marginal benefit increases (regardless of $n$ ). However, she also treats large groups like small groups so that dispersed costs have little influence on behavior.

Our social preference model produces a number of economic implications. First, it admits "moral ambiguity": altruistic behavior in bilateral situations (or small groups) as well as welfare-damaging behavior in large groups when the costs of an action are dispersed among many individuals. Or, to put it in more picturesque terms, both charity donations to a clearly specified victim and tax evasion can be optimal behaviors for the average decider. It therefore shows that there is no contradiction between the experimental evidence on pro-social behavior in distribution games and the assumption of selfish behavior in domains with concentrated benefits and dispersed costs. Second, it implies that insurance coverage matters for medical decision making. Physicians may recommend an expensive but inessential treatment only to those patients whose insurance company pays for the treatment costs. Third, our social preference model predicts that altruism is congestible. Donations can be large for a single victim, but may be very small or zero when they are distributed among many recipients.

Finally, this paper is also related to the current literature on distributive justice that 
asks whether the number $n$ should matter if the welfare of one poor person is traded-off against the welfare of $n$ rich individuals (e.g., Fleurbaey and Tundgodden 2010, Cowell et al. 2010, Voorhoeve 2013). The only empirical study in this literature is Cowell et al. (2010). In a survey, they find that around 50 percent of their subjects think that a poor person should not suffer from a $1 £$ cut in her income when this would create a $100 £$ gain for each of the $n$ rich persons, regardless how large is $n$. For the other 50 percent such a cut is acceptable if $n$ is sufficiently large. In our study, subjects' decisions have monetary consequences. Moreover, we vary the decider's incentives so that we can relate our results to the previous literature on dictator game giving.

The rest of the paper is structured as follows. Section 2 describes the experimental setup. In Section 3, we present the experimental results. In Section 4, we develop a social preference model that rationalizes our results. In Section 5, we discuss the economic implications of this preference model. Section 6 concludes.

\section{Experimental Design}

Basic Set-Up. We adopt the following experimental design to study distributional preferences in games with concentrated benefits and dispersed costs. In each "distribution game", a single decider $D$ chooses the provision $x=0,1, \ldots, 10$ of a good, which affects her own payoff, $\pi_{D}=15+a x$, the payoff of a single receiver $\mathrm{R}, \pi_{R}=5+b x$, and the payoff of $n$ payers $P_{i}, \pi_{P_{i}}=15-c x$, with $i \in\{1, \ldots, n\}$. The receiver has a lower endowment than the other parties so that there exists a motive to redistribute payoffs. Parameters $a, b$ and $c$ vary between treatments and games. In each treatment, the number of payers $n$ is fixed. We consider four treatments with $n$ equal to one, three, six and forty. We call these treatments $P 1, P 3, P 6$, and $P 40$, respectively. Table 1 displays the parameter values for all treatments and games.

\section{[Insert Table 1 about here]}

We briefly describe the distribution games that are relevant for our purpose $2^{2}$ The first four games in each treatment are simple dictator games $(D G)$ between the decider and the receiver. In each dictator game, we have $a=-1$ and $c=0$; the parameter $b$ varies between games. With the dictator games we can test whether subjects' behavior in our experiment is comparable to the behavior observed in previous studies on dictator game

\footnotetext{
${ }^{2}$ Overall, subjects played twelve distribution games in each treatment. We focus on ten of these games in the paper. In the other two games (games 5 and 6 in treatments $P 1, P 3$, and $P 6$ ), we keep the costs per unit provided constant across treatments so that more payers imply lower costs per payer (see Table 1). The results in these games are in line with the interpretation of our main result.
} 
giving (Camerer 2003). In addition, we can follow the approach of AM and use the behavior in these games to classify subjects into different social preference types.

The remaining distribution games have concentrated benefits and dispersed costs. We are interested in the role of efficiency concerns in these games. Will subjects help the receiver even if the provision of the good substantially reduces the group payoff, but costs are distributed among many payers? To what extent do monetary incentives matter for subjects' decisions in these situations?

In the games of the treatments $P 1, P 3$ and $P 6$, we keep the cost per unit and payer (the parameter $c$ ) constant across treatments. The larger the number of payers, the larger is the cost per unit. In four of these games, the provision of the good benefits both the decider and the receiver, but the receiver's benefit decreases across games. We call these games "interested cost dispersion games" $(I C D G)$. In each of these games, we have $a=1.0, c=1.0$; the parameter $b$ varies between games. In the two other games, the decider has no monetary incentives. We call these games "disinterested cost dispersion games" $(I C D G)$. There we have $a=0.0, c=1.0 ; b$ again varies between games. By comparing behavior in the $I C D G$ s and $D C D G$ s we can study the impact of monetary incentives on behavior in situations with concentrated benefits and dispersed costs.

Finally, in the games of the treatment $P 40$, we analyze how subjects trade-off their own and the receiver's payoff against the payers' payoff when the provision of the good becomes very costly for the group. For example, in the disinterested cost dispersion games of the treatments $P 1$ to $P 6$, the negative marginal impact on the group payoff ranges between zero and -5.5 . In comparison, in the treatment $P 40$, the negative marginal impact goes down to -39.0 , which is seven times as large. In the other games of this treatment, we vary the cost per unit and payer $c$ and whether the decider has a monetary incentive or not; the parameter $b$ is kept constant.

Experimental Procedures. In a treatment with $n$ payers, subjects are paired up randomly into groups of size $n+2$. Each subject chooses the provision of the good $x$ in twelve distribution games (see Table 1). After the experiment (that is after all choices have been made), we randomly pick one game for each group that is implemented. We also randomly select one subject from each group that takes on the role of the decider and one subject that takes on the role of the receiver. The other subjects of the group take on the role of payers. The decider's action in the chosen game then determines the payoffs of all group members. Hence, subjects' decisions can only affect their own payoff when they are chosen to be the decider, not when they are in the role of the receiver or of a payer. This is explicitly communicated to participants.

Our procedure implies that the probability that a decision is implemented equals $1 / 12 \times$ $1 / n$ and therefore decreases in the number of payers. In the dictator (and interested 
cost dispersion games), it is cheaper to make more generous (group payoff maximizing) choices when there are many payers. We can check for the existence of such demand effects (Levitt and List 2007) by comparing behavior in the dictator games between treatments. If a fraction of subjects cares for its reputation of being an altruistic person, we should observe that the average provision of the good increases in $n$.

Subjects get no feedback about the actions of others except through their payment after the experiment. When making their decision, subjects receive detailed information about the (potential) consequences of their action on the decision screen: their own payoff, the receiver's payoff, the payoff of each payer, and the group payoff.

The experiment was conducted over the internet and administered by CentERdata, Tilburg University. We obtained the data in anonymized form (this was made clear to participants in the invitation e-mails and on the first screen of the experiment). We recruited 383 subjects through ORSEE (Greiner 2004) from the subject pool of the Munich Experimental Laboratory for Economic and Social Sciences (MELESSA). Participants were students of all faculties of the University of Munich. 98 subjects were randomly assigned to treatment $P 1,101$ to treatment $P 3,91$ to treatment $P 6$ and 93 to treatment $P 40$. On the first screens of the experiment, participants answered several survey questions on demographic variables. We then carefully explained the design using several numerical examples. Subjects could participate in the experiment only if they correctly answered two control questions. Access to the experiment was open for two weeks. Payments were made one week after the experiment. A participant's payoff of $\pi$ tokens was converted into $0.5 \pi$ EUR. Average earnings (which include a 4 EUR show-up fee) were 10.06 EUR.

Conjectures. Previous studies have shown that the dominant behavioral motives in simple distribution games are selfishness, efficiency and the maximization of the payoff of the least well-off individual. In the following, we assume that subjects care about these motives.

Consider any dictator game. The marginal effect of the provision of the good on the decider's payoff and the group payoff is constant across treatments. Also the minmax action (the number $x$ of units that must be provided in order to maximize the welfare of the least well-off individual) does not depend on the number of payers. Hence, if subjects only care about the effect of their action on their own payoff, the group payoff and the payoff of the least well-off individual, the provision of the good in the dictator games is independent of the number of payers.

Consider any cost dispersion game $(I C D G$ or $D C D G)$. When we vary the number of payers, the marginal effect of the provision of the good on the decider's payoff and the minmax action remain constant. However, the marginal effect of the provision of the 
good on the group payoff decreases in the number of payers. Thus, we expect that concerns for efficiency decrease the provision of the good when the number of payers increases.

CONJECTURE 1: In the dictator games, the provision of the good is independent of the number of payers.

CONJECTURE 2: In the cost dispersion games, the provision of the good decreases in the number of payers.

Finally, the variation of the receiver's marginal benefit $b$ in each class of games allows us to check within-subject which motive is on average the stronger one: concerns for efficiency or for the least well-off individual. If efficiency concerns are stronger than concerns for the least well-off individual, the provision of the good should increase in $b$ (and vice versa).

\section{Experimental Results}

\subsection{Average Behavior in the Dictator Games}

We use the dictator games to control for two important issues. First, we check whether dictator game giving in each treatment is comparable to that reported in previous studies. Second, we observe whether the varying probability that a decision becomes implemented changes subjects' behavior through demand effects. Figure 1 shows the average amounts provided in each treatment and dictator game. One third of our subjects are purely selfish and provide 0 units in all dictator games. Over all parameter values and treatments, subjects provided on average 20.4 percent of the maximum possible amount. Hence, average behavior is very similar to typical mean allocations in the studies reported by Camerer (2003). In games 1 and 2, the average provision is 2.43 and 2.47 units, respectively; in games 3 and 4, the average provision is 1.61 and 1.63 units, respectively. Subjects' average reaction to the price of giving is close to the one reported in $\mathrm{AM} \mathrm{H}^{3}$

\section{[Insert Figure 1 about here] [Insert Table 2 about here]}

\footnotetext{
${ }^{3}$ If the relative price of giving (in our case $-a / b$ ) equals 2,1 , and 0.5 , the average provision in $\mathrm{AM}$ is 20.7-21.2, 16.9-24.3 and 30.3-32.3 percent, respectively (see Table 1 in AM). In our data, if the relative price of giving equals $2,1.11$ and 0.5 the average provision is $16.3,16.1$ and 24.3 percent, respectively.
} 
The number of payers has no influence on subjects' decisions. A non-parametric ranksum test does not reject the equality of the distributions of provisions by $n$ in pairwise comparisons ( $\mathrm{p}$-values lie between 0.55 and 0.99 ). Table 2 confirms this result in a linear regression. We regress the number of units provided on the number of payers $n$, the receiver's marginal benefit $b$ and gender. Standard errors are clustered by subject. The number of payers has no significant influence on the provision of the good. Also, subjects do not react differently to changes in $b$ when $n$ changes (see the interaction terms between $b$ and $n$ in the second specification). This confirms Conjecture 1 and shows that there are no demand effects in our experiment.

Like Andreoni and Vesterlund (2001) we find a significant gender-effect, see specification 3 of Table 2. Men provide more of the good than women if the provision of the good increases the group payoff, and less if it decreases the group payoff.

Following AM, we use behavior in the dictator games to classify subjects into selfish, maximin and efficiency types according to the smallest Euclidean (mean square) distance between their choices and the prediction of the pure types. We thereby get a coarse estimate about their dominant behavioral motive in distribution games. Of course, a subject may care for more than one of these motives. Therefore, we also look at average behavior independent of the type. However, as we will see the classification will facilitate the interpretation of the subsequent results.

Over all treatments, 60.6 percent of subjects are classified as selfish, 31.5 percent as maximin, and 7.9 percent as efficiency types. The corresponding numbers in AM are 47.2, 30.4 and 22.4 percent, respectively. We have a somewhat larger share of selfish and fewer efficiency types compared to AM, which may be due to the fact that subjects in our experiment were recruited from all faculties while AM had only economics students. Fehr et al. (2006) show that economics students have a higher preference for efficiency. The distribution over types in our sample is almost identical across treatments.$^{5}$

\subsection{The impact of cost dispersion on behavior}

To what extent do subjects reduce the provision of the good when its costs increase while the costs per payer remain constant? Subjects who are motived exclusively by selfishness and/or maximin preferences should provide the same amount in all conditions. However,

\footnotetext{
${ }^{4}$ The utility function of the purely selfish type is given by $U\left(\pi_{D}, \pi_{R}, \pi_{P}\right)=\pi_{D}$, that of the pure maximin type by $U\left(\pi_{D}, \pi_{R}, \pi_{P}\right)=\min \left\{\pi_{D}, \pi_{R}, \pi_{P}\right\}$, and that of the pure efficiency type by $U\left(\pi_{D}, \pi_{R}, \pi_{P}\right)=\pi_{D}+\pi_{R}+P \pi_{P}$. In the four dictator games, the selfish type always provides zero, the maximin type provides 3-4/4/5-6/6-7, and the efficiency type provides 10/10/0/0, respectively.

${ }^{5}$ The share of (weak) selfish types in a given treatment varies between 58.2 and 62.2 percent, the share of (weak) maximin types varies between 28.9 and 36.3 percent, and the share of (weak) efficiency types varies between 5.5 and 9.0 percent, see Table 6 in the Appendix for details.
} 
subjects who are partially motivated by efficiency should reduce the provision of the good when more payers are affected by its costs. Hence, for the cost dispersion games we expect that average provision decreases in the number of payers. In particular, this should be true in the disinterested cost dispersion games where making choices that maximize the group payoff is costless for the decider.

\section{[Insert Figure 2 about here] [Insert Table 3 about here]}

Figure 2 shows the average amounts provided in the interested cost dispersion games. When the number of payers increases from one to three, the average amount provided drops by around 25 percent. In a linear regression, this effect is significant for all games at the 1 percent level (see Table 3). However, when we further increase the number of payers from three to six, the average amount provided remains largely constant. The coefficients of $P 3$ and $P 6$ are not statistically different. Apparently, aggregate behavior becomes unresponsive to increasing costs of provision when the costs per payer remain constant. This result holds if we further increase the number of payers. The average provision in game 7 with six payers is 5.83 . In the corresponding game with 40 payers, the average provision is 5.68.6 Thus, although there are many more payers affected, the provision of the good is essentially the same (when we test for equality of coefficients, the p-value is 0.784 ). The implied average damage for the group payoff is substantial. In treatment $P 40$, for example, the decider and the receiver each gain on average 5.69 tokens through the provision of the good, while the group payoff decreases by 216.22 tokens.

\section{[Insert Figure 3 about here] [Insert Table 4 about here]}

Figure 3 shows the average provision in the disinterested cost dispersion games. When the number of payers increases from one to three, the average amount provided drops by around 33 percent. In a linear regression, this effect is significant at a 1 percent level (see Table 4). When we further increase the number of payers from three to six, the average amount provided again remains constant. The same holds if we increase the number of payers to 40 . When $b=1.0$ and $c=1.0$, the average provision is equal to 3.32 with six payers and equal to 3.40 with 40 payers. Hence, even if it is costless for the decider to make choices that maximize group welfare, subjects become unresponsive to increasing costs of provision when the costs per payer remain constant.

\footnotetext{
${ }^{6}$ In the corresponding game $P 40.5$, parameters are identical to game $P 6.7$ except that $b$ is equal to 1.0 in the former and 0.8 in the latter.
} 
OBSERVATION. Average behavior becomes unresponsive to an increase in provision costs when the costs per payer remain constant. This rejects Conjecture 2. The result holds independent of whether the provision benefits the decider or not.

Can we conclude that our subjects do not care for efficiency? The answer is no. In all types of games of the treatments $P 1, P 3$ and $P 6$, we vary $b$, the receiver's payoff per unit provided. A larger $b$ implies that the provision of the good is less harmful for the group payoff. Efficiency concerns then increase the provision of the good when $b$ increases. Concerns for the least well-off individual decrease the provision of the good when $b$ increases. The data imply that the first effect dominates. The provision of the good significantly increases in $b$ (see Tables 2 to 4 ). Hence, the average decider takes into account the payoff of all parties and has concerns for efficiency when she trades-off the welfare of one individual against the welfare of another individual. However, large groups of payers receive just the same weight as small groups. Consequently, the provision of the good under dispersed costs is substantial even if provision costs become very large. We obtain further information about the behavioral motives that lead to this result if we compare the average behavior of the three preference types. Consider first the average provision in the interested cost dispersion games (with $a=1.0 ; b=0.8$ in $P 1, P 3$ and $P 6 ; b=1.0$ in $P 40 ; c=1.0)$ :

$\begin{array}{lcccc} & P 1.7 & P 3.7 & P 6.7 & P 40.5 \\ \text { Selfish: } & 8.17 & 7.26 & 6.96 & 6.49 \\ \text { Maximin: } & 6.00 & 4.38 & 4.62 & 4.70 \\ \text { Efficiency: } & 9.63 & 2.33 & 2.63 & 3.60\end{array}$

Selfish types on average reduce the provision of the good as the number of payers increases, but at a decreasing rate. For the first two additional payers, provision decreases by 11.1 percent, while for the last 34 additional payers provision decreases by only 6.8 percent. Obviously, they care about the group payoff to some extent, but they do not reduce the provision of the good to low levels if the costs of provision become very large. Maximin types reduce the provision of the good on average by 27.0 percent for the first two additional payers, but then become unresponsive to further changes (which is exactly what we would expect given their dominant behavioral motive). Efficiency types reduce the provision of the good to low levels once it reduces the group payoff (again, this is the expected outcome). Differences in means are significant for the first two additional payers for all types ( $\mathrm{p}$-values for one-sided t-tests $\leq 0.0518$ ), while there are no statistically significant differences for the increases from three to six or 40 payers (p-values $\geq$ $0.2504)$. 
A similar picture obtains if we consider the disinterested cost dispersion games (with $a=0.0 ; b=1.0 ; c=1.0)$ :

$\begin{array}{lcccc} & P 1.11 & P 3.11 & P 6.11 & P 40.10 \\ \text { Selfish: } & 4.88 & 3.52 & 3.32 & 2.94 \\ \text { Maximin: } & 5.00 & 3.69 & 4.42 & 4.61 \\ \text { Efficiency: } & 5.63 & 0.56 & 0.13 & 1.60\end{array}$

Selfish types again respond to growing costs at a decreasing pace: For the first two additional payers, provision decreases by 27.9 percent $(p$-value $=0.004)$, while for the last 34 payers provision only decreases by 11.4 percent ( $\mathrm{p}$-value $=0.267$ ). So even if is costless to make choices that maximize the group payoff, selfish types become insensitive to increasing provision costs as long as the costs per payer remain constant. For maximin types, it hardly makes a difference whether the number of payers is one or 40 . Efficiency types drastically reduce the provision of the good once it decreases the group payoff.

\section{Rationalizing Behavior with CES-Preferences}

We develop a parsimonious social preference model that can rationalize our experimental data. In particular, it will describe why the average decider has concerns for efficiency when it comes to trade-offs between the welfare of two individuals, and at the same time neglects large provision costs when they are dispersed among many payers. In the next section, we apply our social preference model to a number of economic decisions where distributional preferences matter.

The model has to capture the following observations: (a) giving in dictator games is strictly positive and independent of the number of payers; (b) the provision of the good decreases if we increase the number of payers from one to three, but (c) converges to a positive value if we further increase the number of payers; $(d)$ the provision of the good increases in $b$, regardless of the number of payers.

AM rationalize the behavior of the three preference types in dictator games with the following CES-utility function:

$$
U^{A M}\left(\pi_{D}, \pi_{R}\right)=\left(\alpha \pi_{D}^{\rho}+(1-\alpha) \pi_{R}^{\rho}\right)^{1 / \rho}
$$

It provides a good fit for all preference types. The parameter $\alpha$ represents the weight of the own payoff relative to the payoff of others; the parameter $\rho$ defines the convexity of the utility function. For the three preference types, AM estimate $\alpha$ in the range between 0.5 and 0.8 , and $\rho$ in the range between -0.4 and 0.7 . We generalize AM's utility function 
to a setting with three parties where one party may consist of several individuals:

$$
U\left(\pi_{D}, \pi_{R}, \pi_{P}\right)=\left(\frac{\alpha}{f(n)} \pi_{D}^{\rho}+\frac{0.5(1-\alpha)}{f(n)} \pi_{R}^{\rho}+\left(1-\frac{\alpha}{f(n)}-\frac{0.5(1-\alpha)}{f(n)}\right) \pi_{P}^{\rho}\right)^{1 / \rho}
$$

Compared to $U^{A M}$ our utility function $U$ contains one more object, $f(n)$. It captures the weight on a payer's payoff versus the own and the receiver's payoff as a function of the number of payers. We normalize $f(0)=0.5(1+\alpha)$ so that for $n=0$ our utility function $U$ collapses to a linear transformation of $U^{A M}$. Moreover, we set $f(1)=1$ so that for $n=1$ the receiver's and a payer's payoff have the same weight in the utility function (note that the second term in $U$ is multiplied by 0.5 ).

We show that if $\alpha<1,0<\rho<1$ and $f$ is a weakly increasing function with $f(40) \approx$ $f(6) \approx f(3)>1$, then a decider with utility function $U$ exhibits the behaviors (a) to (d). Recall that in each game $\pi_{D}=15+a x, \pi_{R}=5+b x, \pi_{P}=15-c x$. For convenience, we treat $x \in[0,10]$ as a continuous variable. We abbreviate $U(x)=V(x)^{1 / \rho}$. The first-order derivative is then

$$
\begin{aligned}
U^{\prime}(x)= & V(x)^{1 / \rho-1} \frac{\alpha a}{f(n)} \pi_{D}^{\rho-1}+V(x)^{1 / \rho-1} \frac{0.5(1-\alpha) b}{f(n)} \pi_{R}^{\rho-1} \\
& -V(x)^{1 / \rho-1}\left(1-\frac{\alpha}{f(n)}-\frac{0.5(1-\alpha)}{f(n)}\right) c \pi_{P}^{\rho-1} .
\end{aligned}
$$

For all games, an interior optimum is characterized by the implicit function

$$
\alpha a \pi_{D}^{\rho-1}+0.5(1-\alpha) b \pi_{R}^{\rho-1}-(f(n)-\alpha-0.5(1-\alpha)) c \pi_{P}^{\rho-1}=0 .
$$

We prove property (a). In each dictator game, we have $a<0, b>0$ and $c=0$. Since $\rho<1$, the first and second term in (1) strictly decrease in $x$, while the third term equals 0 . Hence, there is a unique optimum, which is independent of $n$ and strictly positive if $\alpha$ is not too close to 1 .

We prove property (b) and (c). In each game that is not a dictator game, we have $a \geq 0$, $b>0$ and $c>0$. Since $\rho<1$, the first term in (1) equals 0 or strictly decreases in $x$, the second term strictly decreases in $x$, and the third term strictly increases in $x$. Consequently, there is a unique optimum in each cost dispersion game. Property (b) directly follows from the assumption that $f(1)=1<f(3)$, and property (c) from the assumption that $f(3) \approx f(6) \approx f(40)$.

We prove property $(\mathrm{d})$. From the implicit function we get

$$
\frac{d x}{d b}=\frac{(1-\rho)^{-1} 0.5(1-\alpha) \pi_{R}^{\rho-1}\left(1-(1-\rho) b x \pi_{R}^{-1}\right)}{\alpha a^{2} \pi_{D}^{\rho-2}+0.5(1-\alpha) b^{2} \pi_{R}^{\rho-2}+(f(n)-\alpha-0.5(1-\alpha)) c^{2} \pi_{P}^{\rho-2}} .
$$

Since alpha $<1$ and $0<\rho<1$, this expression is strictly positive. Hence, the optimal action in each game increases in $b$. 
The important feature of utility function $U$ is that it captures distributional preferences in small and large groups. All important behavioral motivations that we observe in the distribution games - selfishness, efficiency, and concerns for the least well-off individual - can be active in $U$ independent of group size. However, if we assume that the weight on the payers's payoff converges to a fixed value, i.e., $\lim _{n \rightarrow \infty} f(n)=f<\infty$, then large groups receive the same weight as small groups. Consequently, large costs that are dispersed among many individuals have relatively little influence on behavior. In the next section, we discuss the economic implications of our preference model on social behavior, medical decision making and charity donations.

\section{Economic Implications}

Moral ambiguity. Our utility function $U$ suggests that both pro- and asocial acts can be optimal at the same time for the average decider. Take, for example, donations $x \geq 0$ to a clearly specified, needy receiver and tax evasion $z \geq 0$. The decider maximizes utility from both activities, possibly at different points in time and with a different mindset, but with the same distributional preferences. A donation is a transfer of $x$ from the decider to some receiver. The monetary gain of tax evasion for the decider is $z$ and the cost of tax evasion per (tax-)payer is $\frac{z}{n}$. Let $\pi_{D}, \pi_{R}$ and $\pi_{P}$ be the initial endowments of the decider, receiver and each payer, respectively. The decider will donate a positive amount to the receiver if at $x=0$

$$
\frac{\partial}{\partial x}\left[\frac{\alpha}{f(n)}\left(\pi_{D}-x\right)^{\rho}\right]+\frac{\partial}{\partial x}\left[\frac{0.5(1-\alpha)}{f(n)}\left(\pi_{R}+x\right)^{\rho}\right]>0,
$$

which is the case when

$$
-\alpha \pi_{D}^{\rho-1}+0.5(1-\alpha) \pi_{R}^{\rho-1}>0 .
$$

This condition holds for $\alpha<1$ if the receiver is sufficiently poor relative to the decider. However, the decider will also evade taxes if at $z=0$

$$
\frac{\partial}{\partial z}\left[\frac{\alpha}{f(n)}\left(\pi_{D}+z\right)^{\rho}\right]+\frac{\partial}{\partial z}\left[\left(1-\frac{\alpha}{f(n)}-\frac{0.5(1-\alpha)}{f(n)}\right)\left(\pi_{P}-\frac{z}{n}\right)^{\rho}\right]>0 .
$$

Since $f(n)$ is an increasing function that converges to $f<\infty$, this inequality is implied by

$$
\alpha \pi_{D}^{\rho-1}+\frac{1}{n}(f-\alpha-0.5(1-\alpha)) \pi_{P}^{\rho-1}>0 .
$$

The second term on the left-hand side vanishes for $n \rightarrow \infty$. The decider hides a positive amount of her income if the costs of tax evasion are dispersed among sufficiently many payers. So the optimal levels of donations and tax evasion can be strictly positive at the same time. A similar case can be made for corruption or the provision of local public 
goods at the expense of a national tax base. For economic theory this means that in domains with concentrated benefits and dispersed costs, the assumption of selfishness is a good approximation of the average decider's utilitarian preferences.

Concerns for the patient, not for insurance holders. The idea that physicians have concerns for the patient is well-established in the health economics literature (see McGuire 2000, Chapter 6, for a review). There is, however, no consensus how to model them. Several papers assume that physicians' utility function is given by $U\left(\pi_{D}, \pi_{R}\right)$, where $\pi_{D}$ is their own income and $\pi_{R}$ the patient's welfare. There are no concerns for the welfare of insurance payers.

Physicians' distributional preferences matter a lot for efficiency in the health care sector. Chandra and Skinner (2012) show in a model of patient demand and health-care supply behavior that the availability of treatments that are on average ineffective create rapid cost growth when patients are fully insured. The key assumption in their analysis is that physicians "want to do everything in their power to cure their patient." Consequently, there is positive supply of treatments with small benefits for the patient, but large costs for insurance holders.

Our social preference model qualifies the assumption that there are concerns for the patient, but not for insurance payers. In the model, the decider takes the welfare of all parties into account and has concerns for efficiency, but gives very little weight to costs that are dispersed among many individuals.

One consequence of this is that insurance protection changes physicians' behavior. Consider a physician who decides whether a treatment should take place $(x=1)$ or not $(x=0)$. Her distributional preferences are given by our utility function $U$. The treatment benefits the patient, but it is not essential for her recovery. The patient has no information about the benefits and costs of the treatment. She therefore relies on the physician's recommendations. Let the physician's remuneration be $a x$, the patient's net benefit (in monetary terms) $b x$, and the costs are $c x$, where $a, b, c$ are positive. Initial endowments are again given by $\pi_{D}, \pi_{R}$ and $\pi_{P}$ (we assume that $\pi_{R}, \pi_{P}>c$ ). Either the patient or her insurance company pay for the costs of treatment. Suppose that the treatment is inefficient in the sense that $a+b<<c$. Will the physician perform the treatment or not?

Assume first that the physician is motivated only by economic self-interest $(\alpha=1)$. She will then perform the treatment, regardless of whether the patient or an insurance company pays for it. Insurance protection creates no additional costs.

Now assume that the physician takes the welfare of other parties into account $(\alpha<1)$. 
She will not perform the treatment in the case of no insurance protection if

$$
\alpha\left[\left(\pi_{D}+a\right)^{\rho}-\pi_{D}^{\rho}\right]<0.5(1-\alpha)\left[\pi_{R}^{\rho}-\left(\pi_{R}+b-c\right)^{\rho}\right]
$$

which holds if concerns for others' welfare are sufficiently strong ( $\alpha$ is not too close to 1 ). In the case of full insurance, the physician will perform the treatment if

$$
\begin{aligned}
& \alpha\left[\left(\pi_{D}+a\right)^{\rho}-\pi_{D}^{\rho}\right]+0.5(1-\alpha)\left[\left(\pi_{R}+b\right)^{\rho}-\pi_{R}^{\rho}\right] \\
& >(f(n)-\alpha-0.5(1-\alpha))\left[\pi_{P}^{\rho}-\left(\pi_{P}-\frac{c}{n}\right)^{\rho}\right] .
\end{aligned}
$$

Since $f(n)$ converges to $f$, the right-hand side converges to 0 as $n$ becomes large. So the physician will perform the treatment if the costs are dispersed among sufficiently many customers of the insurance company. Insurance protection then decreases welfare by $c-a-b>>0$.

Note that these costs of insurance are different from those created by moral hazard. Moral hazard causes costs because the insurance holder (or the physician) exploits a situation of asymmetric information. Our costs of insurance occur because one party (the physician) weights differently the welfare of a single individual (the patient) and the welfare of a party that consists of many individuals (insurance holders).

The empirical evidence on physician choices suggests that insured patients (or patients with better insurance coverage) are more likely to receive high-cost treatments than those without insurance (or less extensive coverage), controlling for other factors that influence physicians' decisions. An early study by Mort et al. (1996) is based on a large number of hypothetical treatment decisions elicited in a nationally representative survey of physicians. McKinlay et al. (1996) use a videotape study to analyze the influence of several socio-economic variables on physicians' decisions. They find that in the subsample of old patients insured ones were more likely to get a cardiac diagnosis for chest pain, which creates greater subsequent costs than the gastrointestinal or psychogenic alternatives. There is also more recent evidence along these lines from administrative data on actual treatment decisions: U.S. data show that Caesarian sections are more likely performed on privately insured mothers than on those without insurance (Movsas et al. 2012), and brand-name drugs are less often substituted for with generic drugs for patients with more lower co-payments for branded drugs in Switzerland (Rischatsch et al. 2013). An implication of these studies is that physicians show more concern for an individual patient's financial situation than for the cost borne by an insurance firm or the tax-payer. To the extent that many Cesarians are not necessary from a purely medical point of view, and that generics and brand-name drugs provide comparable health benefits (even though they might provide higher utility to the patient), these empirical observations imply that the existence of health insurance leads to a welfare loss. At the core of the problem are 
physicians who do not fully take into account treatment costs borne by the health insurance system, i.e., who have the type of preference that we are concerned with in this paper. This may be an important reason for why the spread of health insurance through Medicare has increased medical spending dramatically in the United States (Finkelstein 2007).

Congestible altruism. Our social preference theory predicts that charity donations to a single individual will exceed those to a large group of individuals. For the decider, making a donation to a single recipient is rational as long as

$$
-\alpha \pi_{D}^{\rho-1}+0.5(1-\alpha) \pi_{R}^{\rho-1} \geq 0
$$

while making a donation of $x / n$ to $n$ recipients is only rational as long as

$$
-\alpha \pi_{D}^{\rho-1}+\frac{1}{n}(f(n)-\alpha-0.5(1-\alpha)) \pi_{R}^{\rho-1} \geq 0 .
$$

Hence, for any given $\alpha$ the decider will give nothing if $n$ is sufficiently large. This implies that it may be important for charity organizations to highlight the fate of one specific recipient that depends on the giver's benevolence.

There is some experimental evidence that altruism depends on the number of recipients. Kogut and Ritov (2005) find that contributions for a single victim exceed those for a group of eight victims when these two situations are judged separately. Andreoni (2007) studies how donations depend on the number of receivers. He finds partial congestion: when the number of receivers doubles (and each receiver gets a constant amount per unit provided), the value of a donation to the giver increases by a factor less than two. Specifically, he estimates that one person receiving $x$ is equivalent to $n$ persons receiving $x / n^{\beta}$ where $\beta=0.68$. This means that if we keep constant the marginal effect of a donation on a single recipient, donations increase in $n$, but at a decreasing rate. In our social preference model, if $\lim _{n \rightarrow \infty} f(n)=f<\infty$, altruism is a fully congestible good. Since large groups receive the same weight as small groups, increasing the number of receivers (while keeping fixed the marginal effect per receiver) will not increase donations when there are already many receivers. So in our case, the parameter $\beta$ would be rather close to 0 for $n \geq 3.7$

\footnotetext{
${ }^{7}$ We conjecture that this effect occurs in our experiment, because the group size is not made salient to subjects. In contrast, subjects make decisions for varying group-sizes in Andreoni's (2007) experiment. In their desire to behave consistently, subjects may increase donations in response to an increasing number of receivers. However, note that in the domain of charity donations the the number of receivers (or a variation in the number of receivers) is usually not a salient issue.
} 


\section{Conclusion}

In this paper, we studied distributional preferences in games with concentrated benefits and dispersed costs. We find that the average decider takes into account the payoff of all parties and has efficiency concerns when she trades-off the payoff of two individuals. However, she attaches similar weights to small and large groups of payers. Hence, she neglects large costs that are dispersed among many individuals and therefore provides a good even if if this substantially reduces the total group payoff. This result is independent of whether the decider benefits from the provision of the good or not. We created a social preference model that explains average behavior both in simple dictator games and our cost dispersion games. It can generate pro-social actions in small groups as well as welfare-damaging behavior in situations with concentrated benefits and dispersed costs. In models of health care provision, local public goods, corruption and tax evasion, the assumption of agents who do not care for societal welfare is therefore a good approximation of actual utilitarian preferences and does not conflict with the experimental evidence on other-regarding motivations.

\section{References}

Andreoni, James, And Lise Vesterlund (2001): "Which is the Fair Sex? Gender Differences in Altruism," Quarterly Journal of Economics, 116(1), 293-312.

Andreoni, James, And John Miller (2002): "Giving According to GARP: An Experimental Test of the Consistency of Preferences for Altruism," Econometrica, $70(2), 737-753$.

Andreoni, James (2007): "Giving Gifts to Groups: How Altruism Depends on the Number of Recipients," Journal of Public Economics, 91(9), 1731-1749.

Bandiera, Oriana, Iwan Barankay, and Imran Rasul (2005): "Social Preferences and the Response to Incentives: Evidence from Personnel Data," Quarterly Journal of Economics, 120(3), 917-962.

Chandra, Amitabh, And Jonathan Skinner (2012): "Technology Growth and Expenditure Growth in Health Care," Journal of Economic Literature, 50(3), 645680.

Camerer, Colin (2003): "Behavioral Game Theory." Princeton University Press, Princeton, NJ. 
Charness, Garry, and Matthew Rabin (2002): "Understanding Social Preferences with Simple Tests," Quarterly Journal of Economics, 117(3), 817-869.

Cowell, Frank, Marc Fleurbaey, and Bertil Tungodden (2010): "The Tyranny Puzzle in Welfare Economics: An empirical investigation," unpublished manuscript, London School of Economics.

DellaVigna, Stefano, John List, and Ulrike Malmendier (2012): "Testing for Altruism and Social Pressure in Charitable Giving," Quarterly Journal of Economics, $127(1), 1-56$.

Engelmann, Dirk, and Martin Strobel (2004): "Inequality Aversion, Efficiency, and Maximin Preferences in Simple Distribution Experiments," American Economic Review, 94(4), 857-869.

Fehr, Ernst, Michael Naef, and Klaus Schmidt (2006): "Inequality Aversion, Efficiency, and Maximin Preferences in Simple Distribution Experiments: Comment," American Economic Review, 96(5), 1912-1917.

Fehr, Ernst, And Klaus Schmidt (2006): "The Economics of Fairness, Reciprocity and Altruism - Experimental Evidence and New Theories," In: Serge-Christophe Kolm, Jean Mercier Ythier (Eds.): Handbook on the Economics of Giving, Reciprocity and Altruism, Elsevier, Amsterdam.

Finkelstein, Amy (2007): “The Aggregate Effects of Health Insurance: Evidence from the Introduction of Medicare," Quarterly Journal of Economics, 122(1), 1-37.

Fisman, Raymong, Shachar Kariv, and Daniel Markovits (2007): "Individual Preferences for Giving," American Economic Review, 97(5), 1858-1877.

Fleurbaey, Marc, And Bertil Tungodden (2010): "The Tyranny of NonAggregation versus the Tyranny of Aggregation in Social Cchoices: A Real Dilemma," Economic Theory, 44(3), 399-414.

Greiner, Ben (2004): “An Online Recruitment System for Economic Experiments." In: Kurt Kremer, Volker Macho (Eds.): Forschung und wissenschaftliches Rechnen 2003. GWDG Bericht 63, Goettingen: Ges. fuer Wiss. Datenverarbeitung, 79-93, 2004.

Kogut, Tehila, And Ilana Ritov (2005): "The Singularity Effect of Identified Victims in Separate and Joint Evaluations," Organizational Behavior and Human Decision Processes, 97(2), 106-116. 
Levitt, Steven, And John List (2007): "What Do Laboratory Experiments Measuring Social Preferences Reveal About the Real World," Journal of Economic Perspectives, 21(2), 153-174.

McGuire, Thomas (2000): "Physician Agency." In: Anthony Cuyler, Joseph Newhouse (Eds.): Handbook of Health Economics, Vol. 1A, Amsterdam, North-Holland.

McKinlay, John, Deborah Potter, and Henry Feldman (1996): "Non-Medical Influences on Medical Decision-Making," Social Science and Medicine, 42(5), 769-776.

Menacker, Fay, and Brady Hamilton (2010): "Recent Trends in Cesarean Delivery in the United States," NCHS Data Brief, 35.

Mort, Elizabeth, Jennifer Edwards, David Emmons, Karen Convery, and David Blumenthal (1996): "Physician Response to Patient Insurance Status in Ambulatory Care Clinical Decision-Making: Implications for Quality Care," Medical Care, 34(8), 783-797.

Movsas, Tammy, Eden Wells, Ann Mongoven, and Violanda Grigorescu (2012): “Does Medical Insurance Type (Private vs Public) Influence the Physician's Decision to Perform Caesarean Delivery?," Journal of Medical Ethics, 38(8 ), 470-473.

Rischatsch, Maurus, Maria Trottmann, and Peter Zweifel (2013): "Generic Substitution, Financial Interests, and Imperfect Agency," International Journal of Health Care Finance and Economics, 13(2), 115-138.

Voorhoeve, Alex (2013): "How Should We Aggregate Competing Claims?," unpublished manuscript, Princeton University. 


\begin{tabular}{|c|c|c|c|c|c|c|}
\hline \multirow[b]{2}{*}{ Game } & \multirow[b]{2}{*}{ Label } & \multicolumn{3}{|c|}{ Payoff Parameters } & \multirow{2}{*}{$\begin{array}{c}\text { Number } \\
\text { of Payers } \\
n\end{array}$} & \multirow{2}{*}{$\begin{array}{l}\text { Marginal Impact } \\
\text { on Group Payoff } \\
\qquad a+b-n c\end{array}$} \\
\hline & & $a$ & $b$ & $c$ & & \\
\hline P1.1 & DG & -1.0 & 2.0 & 0.0 & 1 & 1.0 \\
\hline $\mathrm{P} 1.2$ & DG & -1.0 & 1.5 & 0.0 & 1 & 0.5 \\
\hline $\mathrm{P} 1.3$ & $\mathrm{DG}$ & -1.0 & 0.9 & 0.0 & 1 & -0.1 \\
\hline P1.4 & DG & -1.0 & 0.5 & 0.0 & 1 & -0.5 \\
\hline P1.5 & $\mathrm{CD}$ & 0.5 & 0.3 & 1.5 & 1 & -0.7 \\
\hline P1. 6 & $\mathrm{CD}$ & 0.5 & 0.1 & 1.5 & 1 & -0.9 \\
\hline P1.7 & ICDG & 1.0 & 0.8 & 1.0 & 1 & 0.8 \\
\hline P1.8 & ICDG & 1.0 & 0.5 & 1.0 & 1 & 0.5 \\
\hline P1.9 & ICDG & 1.0 & 0.3 & 1.0 & 1 & 0.3 \\
\hline P1.10 & ICDG & 1.0 & 0.1 & 1.0 & 1 & 0.1 \\
\hline P1.11 & DCDG & 0.0 & 1.0 & 1.0 & 1 & 0.0 \\
\hline $\mathrm{P} 1.12$ & DCDG & 0.0 & 0.5 & 1.0 & 1 & -0.5 \\
\hline P3.1 & DG & -1.0 & 2.0 & 0.0 & 3 & 1.0 \\
\hline P3.2 & DG & -1.0 & 1.5 & 0.0 & 3 & 0.5 \\
\hline P3.3 & $\mathrm{DG}$ & -1.0 & 0.9 & 0.0 & 3 & -0.1 \\
\hline P3.4 & $\mathrm{DG}$ & -1.0 & 0.5 & 0.0 & 3 & -0.5 \\
\hline P3.5 & $\mathrm{CD}$ & 0.5 & 0.3 & 0.5 & 3 & -0.7 \\
\hline P3.6 & $\mathrm{CD}$ & 0.5 & 0.1 & 0.5 & 3 & -0.9 \\
\hline P3.7 & ICDG & 1.0 & 0.8 & 1.0 & 3 & -1.2 \\
\hline P3.8 & ICDG & 1.0 & 0.5 & 1.0 & 3 & -1.5 \\
\hline P3.9 & ICDG & 1.0 & 0.3 & 1.0 & 3 & -1.7 \\
\hline P3.10 & ICDG & 1.0 & 0.1 & 1.0 & 3 & -1.9 \\
\hline P3.11 & DCDG & 0.0 & 1.0 & 1.0 & 3 & -2.0 \\
\hline P3.12 & DCDG & 0.0 & 0.5 & 1.0 & 3 & -2.5 \\
\hline
\end{tabular}




\begin{tabular}{|c|c|c|c|c|c|c|}
\hline \multirow[b]{2}{*}{ Game } & \multirow[b]{2}{*}{ Label } & \multicolumn{3}{|c|}{ Payoff Parameters } & \multirow{2}{*}{$\begin{array}{c}\text { Number } \\
\text { of Payers } \\
n\end{array}$} & \multirow{2}{*}{$\begin{array}{l}\text { Marginal Impact } \\
\text { on Group Payoff } \\
\\
\quad a+b-n c\end{array}$} \\
\hline & & $a$ & $b$ & $c$ & & \\
\hline P6.1 & DG & -1.0 & 2.0 & 0.0 & 6 & 1.0 \\
\hline $\mathrm{P} 6.2$ & $\mathrm{DG}$ & -1.0 & 1.5 & 0.0 & 6 & 0.5 \\
\hline P6.3 & $\mathrm{DG}$ & -1.0 & 0.9 & 0.0 & 6 & -0.1 \\
\hline $\mathrm{P} 6.4$ & $\mathrm{DG}$ & -1.0 & 0.5 & 0.0 & 6 & -0.5 \\
\hline P6.5 & $\mathrm{CD}$ & 0.5 & 0.3 & 0.25 & 6 & -0.7 \\
\hline P6.6 & $\mathrm{CD}$ & 0.5 & 0.1 & 0.25 & 6 & -0.9 \\
\hline P6.7 & ICDG & 1.0 & 0.8 & 1.0 & 6 & -4.2 \\
\hline P6.8 & ICDG & 1.0 & 0.5 & 1.0 & 6 & -4.5 \\
\hline P6.9 & ICDG & 1.0 & 0.3 & 1.0 & 6 & -4.7 \\
\hline P6.10 & ICDG & 1.0 & 0.1 & 1.0 & 6 & -4.9 \\
\hline P6.11 & DCDG & 0.0 & 1.0 & 1.0 & 6 & -5.0 \\
\hline P6.12 & DCDG & 0.0 & 0.5 & 1.0 & 6 & -5.5 \\
\hline P 40.1 & DG & -1.0 & 2.0 & 0.0 & 40 & 1.0 \\
\hline P 40.2 & $\mathrm{DG}$ & -1.0 & 1.5 & 0.0 & 40 & 0.5 \\
\hline P 40.3 & $\mathrm{DG}$ & -1.0 & 0.9 & 0.0 & 40 & -0.1 \\
\hline P40.4 & $\mathrm{DG}$ & -1.0 & 0.5 & 0.0 & 40 & -0.5 \\
\hline P40.5 & ICDG & 1.0 & 1.0 & 1.0 & 40 & -38.0 \\
\hline P40.6 & ICDG & 1.0 & 1.0 & 0.8 & 40 & -30.0 \\
\hline P40.7 & ICDG & 1.0 & 1.0 & 0.6 & 40 & -22.0 \\
\hline P40.8 & ICDG & 1.0 & 1.0 & 0.4 & 40 & -14.0 \\
\hline P40.9 & ICDG & 1.0 & 1.0 & 0.2 & 40 & -6.0 \\
\hline P40.10 & DCDG & 0.0 & 1.0 & 1.0 & 40 & -39.0 \\
\hline P40.11 & DCDG & 0.0 & 1.0 & 0.5 & 40 & -19.0 \\
\hline P40.12 & DCDG & 0.0 & 1.0 & 0.1 & 40 & -3.0 \\
\hline
\end{tabular}

Note: Games P1.5, P1.6, P3.5, P3.6, P6.5, and P6.6 are not considered in this paper. 
TABLE 2 - Behavior in dictator games

Games 1-4, all treatments

\begin{tabular}{|c|c|c|c|}
\hline Dependent variable: units provided & (1) & $(2)$ & $(3)$ \\
\hline \multirow[t]{2}{*}{$\mathrm{b}$} & $0.656^{* * *}$ & $0.648^{* * *}$ & $0.224^{*}$ \\
\hline & [0.117] & {$[0.231]$} & {$[0.121]$} \\
\hline \multirow[t]{2}{*}{ P3 } & -0.143 & -0.234 & 0.185 \\
\hline & {$[0.278]$} & {$[0.409]$} & {$[0.398]$} \\
\hline \multirow[t]{2}{*}{$\mathrm{P} 6$} & -0.019 & -0.097 & 0.173 \\
\hline & {$[0.309]$} & {$[0.440]$} & {$[0.400]$} \\
\hline \multirow[t]{2}{*}{$\mathrm{P} 42$} & -0.052 & 0.079 & 0.581 \\
\hline & {$[0.293]$} & {$[0.446]$} & {$[0.414]$} \\
\hline \multirow[t]{2}{*}{ Male } & 0.086 & 0.086 & -0.470 \\
\hline & {$[0.211]$} & {$[0.211]$} & {$[0.455]$} \\
\hline \multirow[t]{2}{*}{$b^{*}$ male } & & & $0.905^{* * *}$ \\
\hline & & & {$[0.234]$} \\
\hline \multirow[t]{2}{*}{ P3*male } & & & -0.615 \\
\hline & & & {$[0.554]$} \\
\hline \multirow[t]{2}{*}{$\mathrm{P} 6^{*}$ male } & & & -0.289 \\
\hline & & & {$[0.630]$} \\
\hline \multirow[t]{2}{*}{ P40*male } & & & $-1.323^{* *}$ \\
\hline & & & {$[0.577]$} \\
\hline \multirow[t]{2}{*}{$b^{*} \mathrm{P} 3$} & & 0.075 & \\
\hline & & {$[0.321]$} & \\
\hline \multirow[t]{2}{*}{$b^{*} \mathrm{P} 6$} & & 0.064 & \\
\hline & & {$[0.336]$} & \\
\hline \multirow[t]{2}{*}{$\mathrm{b}^{*} \mathrm{P} 40$} & & -0.107 & \\
\hline & & [0.331] & \\
\hline \multirow[t]{2}{*}{ Constant } & $1.245^{* * *}$ & $1.256^{* * *}$ & $1.481^{* * *}$ \\
\hline & {$[0.267]$} & [0.308] & {$[0.285]$} \\
\hline Observations & 1,532 & 1,532 & 1,532 \\
\hline$R^{2}$ & 0.021 & 0.021 & 0.039 \\
\hline
\end{tabular}

Robust standard errors in parentheses, clustering of standard errors by respondent

$$
\text { *** } \mathrm{p}<0.01, * * \mathrm{p}<0.05, * \mathrm{p}<0.1
$$


TABLE 3 - Behavior in interested cost dispersion games

Games 7-10, treatments P1, P3 and P6

\begin{tabular}{|c|c|c|c|}
\hline Dependent variable: units provided & (1) & $(2)$ & $(3)$ \\
\hline \multirow[t]{2}{*}{$\mathrm{b}$} & $0.975^{* * *}$ & $0.980^{* *}$ & $0.791^{* * *}$ \\
\hline & [0.201] & [0.388] & {$[0.267]$} \\
\hline \multirow[t]{2}{*}{ P3 } & $-1.866^{* * *}$ & $-1.911^{* * *}$ & $-2.293^{* * *}$ \\
\hline & {$[0.433]$} & [0.519] & {$[0.565]$} \\
\hline \multirow[t]{2}{*}{$\mathrm{P} 6$} & $-2.020^{* * *}$ & $-1.962^{* * *}$ & $-1.956^{* * *}$ \\
\hline & {$[0.489]$} & {$[0.565]$} & {$[0.607]$} \\
\hline \multirow[t]{2}{*}{$b^{*}$ male } & & & 0.377 \\
\hline & & & {$[0.404]$} \\
\hline \multirow[t]{2}{*}{ P3*male } & & & 0.791 \\
\hline & & & {$[0.855]$} \\
\hline \multirow[t]{2}{*}{ P6*male } & & & -0.243 \\
\hline & & & {$[1.007]$} \\
\hline \multirow[t]{2}{*}{ Male } & -0.464 & -0.464 & -0.830 \\
\hline & {$[0.397]$} & {$[0.397]$} & {$[0.572]$} \\
\hline \multirow[t]{2}{*}{$b^{*} \mathrm{P} 3$} & & 0.107 & \\
\hline & & {$[0.513]$} & \\
\hline \multirow[t]{2}{*}{$\mathrm{b}^{*} \mathrm{P} 6$} & & -0.135 & \\
\hline & & {$[0.500]$} & \\
\hline \multirow[t]{2}{*}{ Constant } & $7.281^{* * *}$ & $7.279^{* * *}$ & $7.468^{* * *}$ \\
\hline & {$[0.348]$} & {$[0.384]$} & {$[0.383]$} \\
\hline Observations & 1,160 & 1,160 & 1,160 \\
\hline$R^{2}$ & 0.068 & 0.068 & 0.072 \\
\hline
\end{tabular}

Robust standard errors in parentheses, clustered by respondent

$$
* * * \mathrm{p}<0.01, * * \mathrm{p}<0.05,{ }^{*} \mathrm{p}<0.1
$$


TABLE 4 - Behavior in disinterested cost dispersion games Games 11-12, treatments P1, P3 and P6

\begin{tabular}{|c|c|c|c|}
\hline Dependent variable: units provided & $(1)$ & $(2)$ & $(3)$ \\
\hline \multirow[t]{2}{*}{$\mathrm{b}$} & $0.807^{* * *}$ & $1.204^{*}$ & $0.770^{*}$ \\
\hline & {$[0.306]$} & {$[0.619]$} & {$[0.397]$} \\
\hline \multirow[t]{2}{*}{ P3 } & $-1.562^{* * *}$ & -1.149 & $-1.076^{* *}$ \\
\hline & {$[0.346]$} & {$[0.744]$} & {$[0.536]$} \\
\hline \multirow[t]{2}{*}{ P6 } & $-1.625^{* * *}$ & -1.134 & $-1.040^{*}$ \\
\hline & [0.381] & {$[0.741]$} & {$[0.560]$} \\
\hline \multirow[t]{2}{*}{$b^{*}$ male } & & & 0.075 \\
\hline & & & {$[0.616]$} \\
\hline \multirow[t]{2}{*}{ P3*male } & & & -0.911 \\
\hline & & & [0.698] \\
\hline \multirow[t]{2}{*}{$\mathrm{P} 6^{*}$ male } & & & $-1.257^{*}$ \\
\hline & & & {$[0.750]$} \\
\hline \multirow[t]{2}{*}{ Male } & $-0.878^{* * *}$ & $-0.878^{* * *}$ & -0.232 \\
\hline & {$[0.302]$} & [0.303] & {$[0.723]$} \\
\hline \multirow[t]{2}{*}{$b^{*} \mathrm{P} 3$} & & -0.551 & \\
\hline & & {$[0.800]$} & \\
\hline \multirow[t]{2}{*}{$b^{*} \mathrm{P} 6$} & & -0.655 & \\
\hline & & {$[0.758]$} & \\
\hline \multirow[t]{2}{*}{ Constant } & $4.539^{* * *}$ & $4.242^{* * *}$ & $4.194^{* * *}$ \\
\hline & {$[0.406]$} & {$[0.604]$} & {$[0.512]$} \\
\hline Observations & 580 & 580 & 580 \\
\hline$R^{2}$ & 0.084 & 0.085 & 0.091 \\
\hline
\end{tabular}

Robust standard errors in brackets, clustered by respondent

$$
\text { *** } \mathrm{p}<0.01, * * \mathrm{p}<0.05, * \mathrm{p}<0.1
$$




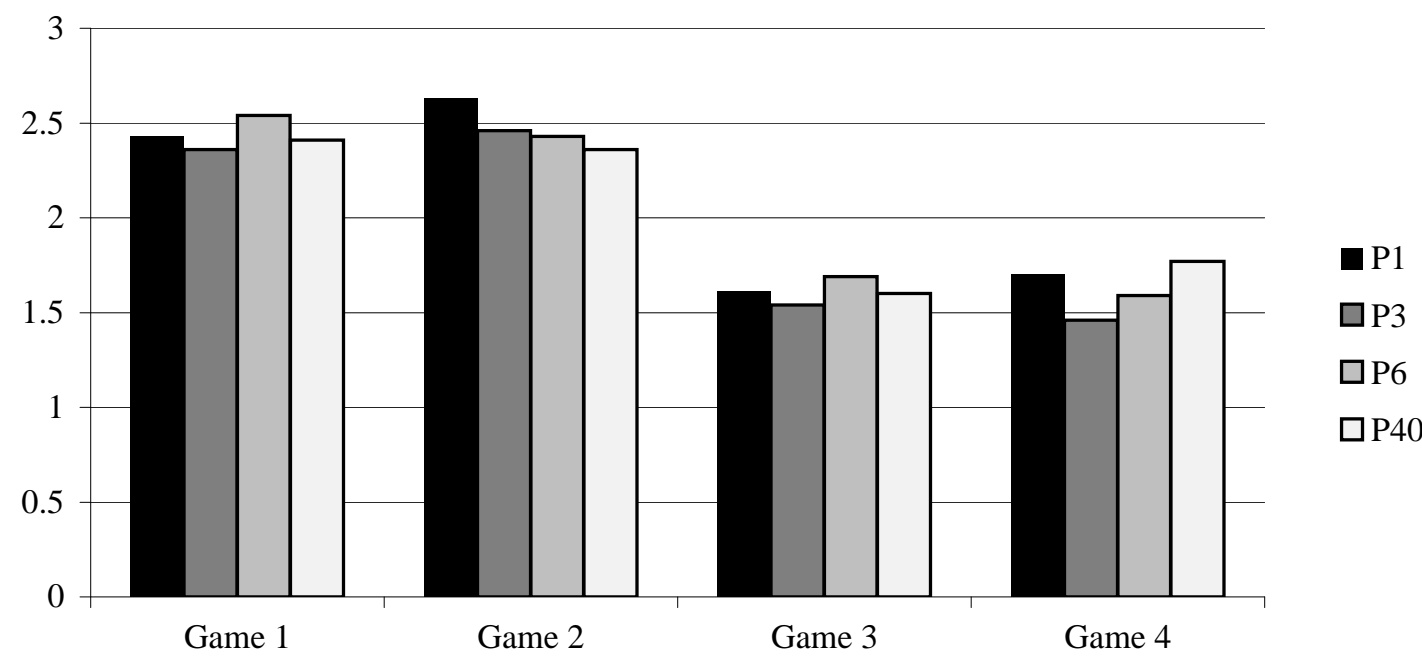

Figure 1: Average Provision in the Dictator Games

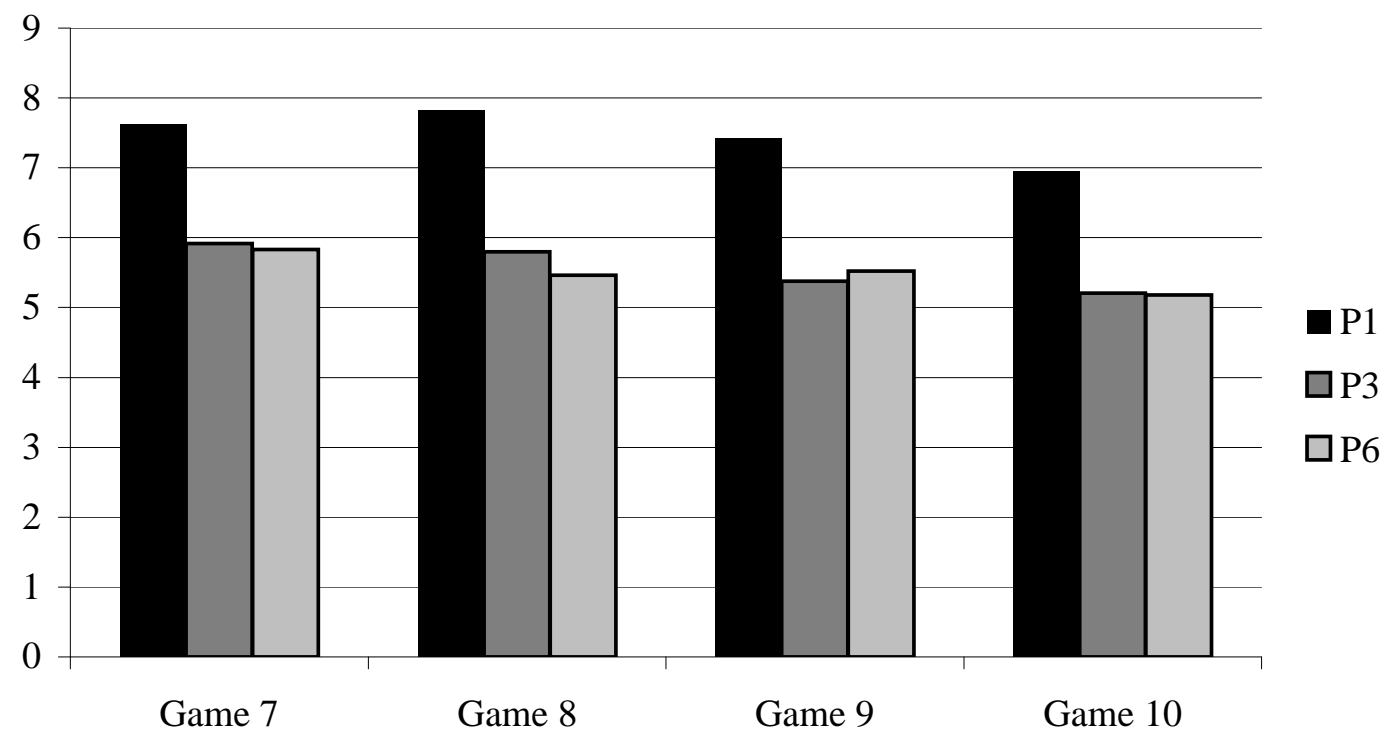

Figure 2: Average Provision in the Interested Cost Dispersion Games 


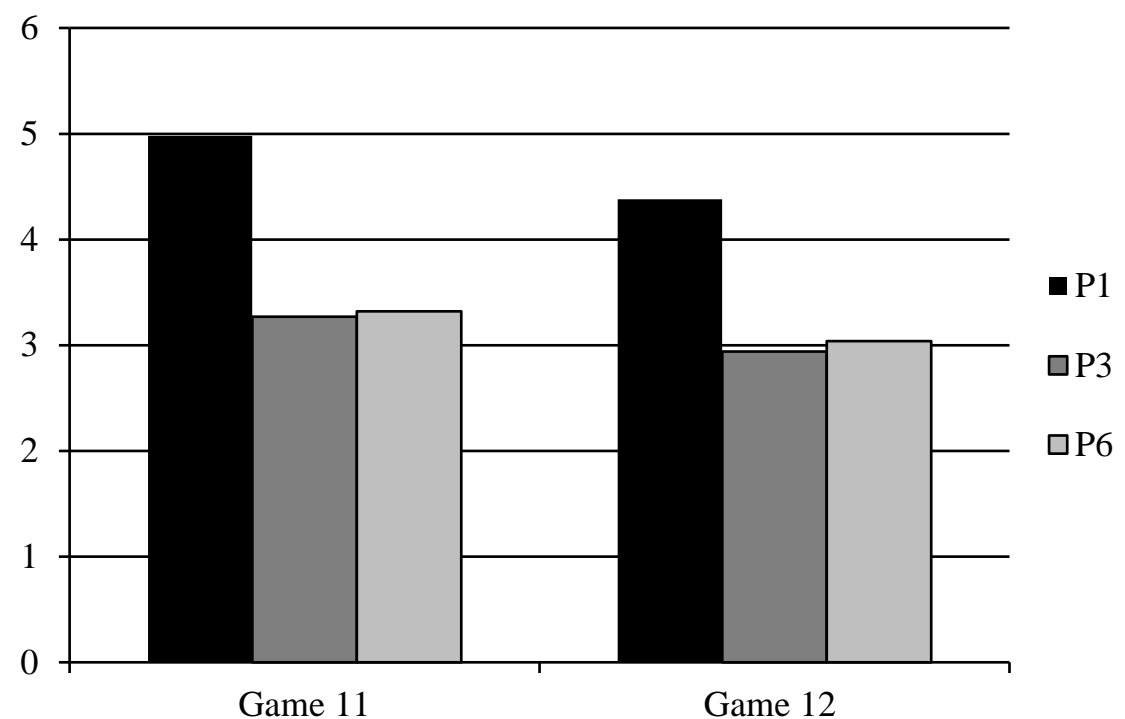

Figure 3: Average Provision in the Disinterested Cost Dispersion Games 


\section{Appendix}

TABLE 5 - Variable Definitions

\begin{tabular}{|c|c|c|}
\hline Variable & Range & Definition \\
\hline $\mathrm{a}$ & $\{-1 ; 0 ; 0.5 ; 1\}$ & $\begin{array}{l}\text { Cost/benefit (per unit } \mathrm{x} \text { of the good) accru- } \\
\text { ing to the decider }\end{array}$ \\
\hline $\mathrm{b}$ & $\{0.1 ; 0.3 ; 0.5 ; 0.9 ; 1.5 ; 2.0\}$ & $\begin{array}{l}\text { Benefit (per unit } \mathrm{x} \text { of the good) accruing to } \\
\text { the receiver }\end{array}$ \\
\hline $\mathrm{c}$ & $\{0 ; 0.1 ; 0.2 ; 0.25 ; 0.4 ; 0.6 ; 0.8 ; 1.0\}$ & $\begin{array}{l}\text { Cost (per unit } \mathrm{x} \text { of the good) accruing to each } \\
\text { of the payers }\end{array}$ \\
\hline $\mathrm{P} 1$ & $\{0 ; 1\}$ & $\begin{array}{l}\text { Dummy indicating that subject was ran- } \\
\text { domly assigned to a group of } 1 \text { payer }\end{array}$ \\
\hline P3 & $\{0 ; 1\}$ & $\begin{array}{l}\text { Dummy indicating that subject was ran- } \\
\text { domly assigned to a group of } 3 \text { payers }\end{array}$ \\
\hline $\mathrm{P} 6$ & $\{0 ; 1\}$ & $\begin{array}{l}\text { Dummy indicating that subject was ran- } \\
\text { domly assigned to a group of } 6 \text { payers }\end{array}$ \\
\hline $\mathrm{P} 40$ & $\{0 ; 1\}$ & $\begin{array}{l}\text { Dummy indicating that subject was ran- } \\
\text { domly assigned to a group of } 40 \text { payers }\end{array}$ \\
\hline Male & $\{0 ; 1\}$ & Dummy indicating that respondent is male \\
\hline
\end{tabular}


TABLE 6 - Average behavior of selfish, maximin and efficiency types

\begin{tabular}{|c|c|c|c|c|c|c|c|c|}
\hline \multirow[b]{2}{*}{ Game } & \multicolumn{2}{|c|}{ All } & \multicolumn{2}{|l|}{ Selfish } & \multicolumn{2}{|l|}{ Maximin } & \multicolumn{2}{|c|}{ Efficiency } \\
\hline & av & $\mathrm{sd}$ & av & sd & av & $\mathrm{sd}$ & av & $\mathrm{sd}$ \\
\hline & $N=98$ & & $N=58(59,8 \%)$ & & $N=31(32,0 \%)$ & & $N=8(8,2 \%)$ & \\
\hline $\mathrm{P} 1.1$ & 2.43 & 2.96 & 0.79 & 1.50 & 3.90 & 2.04 & 8.88 & 2.23 \\
\hline $\mathrm{P} 1.2$ & 2.63 & 3.05 & 0.72 & 1.20 & 4.19 & 1.80 & 9.50 & 0.93 \\
\hline $\mathrm{P} 1.3$ & 1.61 & 2.11 & 0.45 & 0.94 & 3.90 & 1.30 & 1.38 & 3.50 \\
\hline $\mathrm{P} 1.4$ & 1.70 & 2.39 & 0.43 & 1.09 & 4.35 & 2.21 & 0.88 & 1.64 \\
\hline P1.5 & 5.16 & 3.97 & 6.41 & 4.10 & 3.71 & 2.73 & 1.13 & 2.23 \\
\hline P1.6 & 5.03 & 4.07 & 6.41 & 4.15 & 3.29 & 2.70 & 1.13 & 2.80 \\
\hline P1.7 & 7.62 & 2.78 & 8.17 & 2.80 & 6.00 & 2.31 & 9.63 & 1.06 \\
\hline P1.8 & 7.82 & 2.70 & 8.52 & 2.55 & 6.13 & 2.50 & 9.00 & 1.41 \\
\hline P1.9 & 7.42 & 2.95 & 8.19 & 2.72 & 5.45 & 2.66 & 9.13 & 1.81 \\
\hline $\mathrm{P} 1.10$ & 6.94 & 3.52 & 7.78 & 3.13 & 5.06 & 3.60 & 7.75 & 3.58 \\
\hline $\mathrm{P} 1.11$ & 4.98 & 2.30 & 4.88 & 2.45 & 5.00 & 1.79 & 5.63 & 3.20 \\
\hline $\mathrm{P} 1.12$ & 4.38 & 3.11 & 4.36 & 3.41 & 4.81 & 2.15 & 3.38 & 3.89 \\
\hline & $N=101$ & & $N=62(62,0 \%)$ & & $N=29(29,0 \%)$ & & $N=9(9,0 \%)$ & \\
\hline P3.1 & 2.36 & 2.91 & 0.74 & 1.27 & 3.93 & 1.83 & 8.67 & 2.69 \\
\hline P3.2 & 2.46 & 2.86 & 0.74 & 1.24 & 4.07 & 1.36 & 8.22 & 2.68 \\
\hline P3.3 & 1.54 & 2.07 & 0.48 & 1.00 & 4.34 & 1.26 & 0.00 & 0.00 \\
\hline P3.4 & 1.46 & 2.26 & 0.42 & 0.95 & 4.17 & 2.35 & 0.00 & 0.00 \\
\hline P3.5 & 0.33 & 3.55 & 7.23 & 3.41 & 5.86 & 2.66 & 1.22 & 2.44 \\
\hline P3.6 & 5.80 & 3.93 & 6.87 & 3.74 & 5.07 & 3.54 & 1.44 & 2.40 \\
\hline P3.7 & 5.92 & 3.55 & 7.26 & 3.27 & 4.38 & 2.44 & 2.33 & 3.74 \\
\hline P3.8 & 5.80 & 3.93 & 7.23 & 3.13 & 4.00 & 2.63 & 2.44 & 3.47 \\
\hline P3.9 & 5.38 & 3.62 & 6.85 & 3.33 & 3.66 & 2.74 & 1.33 & 1.80 \\
\hline P3.10 & 5.21 & 3.90 & 6.84 & 3.56 & 3.03 & 2.77 & 1.56 & 3.32 \\
\hline P3.11 & 3.27 & 2.91 & 3.52 & 2.98 & 3.69 & 2.65 & 0.56 & 1.67 \\
\hline P3.12 & 2.94 & 2.96 & 2.98 & 3.11 & 3.66 & 2.58 & 0.67 & 2.00 \\
\hline
\end{tabular}


TABLE 6 (Cont'd) - Average behavior of selfish, maximin and efficiency types

\begin{tabular}{|c|c|c|c|c|c|c|c|c|}
\hline \multirow[b]{2}{*}{ Game } & \multicolumn{2}{|c|}{ All } & \multicolumn{2}{|l|}{ Selfish } & \multicolumn{2}{|l|}{ Maximin } & \multicolumn{2}{|c|}{ Efficiency } \\
\hline & av & $\mathrm{sd}$ & av & $\mathrm{sd}$ & av & $\mathrm{sd}$ & av & $\mathrm{sd}$ \\
\hline & $N=91$ & & $N=56(62,2 \%)$ & & $N=26(28,9 \%)$ & & $N=8(8,9 \%)$ & \\
\hline P6.1 & 2.54 & 3.01 & 0.86 & 1.15 & 3.88 & 2.21 & 9.63 & 1.06 \\
\hline P6.2 & 2.43 & 2.86 & 0.71 & 1.16 & 3.92 & 1.09 & 9.25 & 2.12 \\
\hline P6.3 & 1.69 & 2.36 & 0.25 & 0.55 & 4.69 & 1.23 & 2.25 & 3.65 \\
\hline P6.4 & 1.59 & 2.53 & 0.27 & 0.70 & 4.73 & 2.57 & 0.88 & 1.81 \\
\hline P6.5 & 6.53 & 3.93 & 7.11 & 3.65 & 6.42 & 3.73 & 3.63 & 5.01 \\
\hline P6.6 & 6.38 & 4.12 & 7.41 & 3.60 & 5.85 & 4.22 & 1.75 & 3.62 \\
\hline P6.7 & 5.84 & 3.91 & 6.96 & 3.73 & 4.62 & 3.10 & 2.63 & 4.57 \\
\hline P6.8 & 5.46 & 3.97 & 6.73 & 3.92 & 3.96 & 2.76 & 2.13 & 4.02 \\
\hline P6.9 & 5.52 & 4.14 & 6.93 & 3.90 & 3.81 & 3.37 & 1.88 & 3.72 \\
\hline P6.10 & 5.18 & 4.24 & 6.52 & 4.09 & 3.46 & 3.49 & 2.00 & 3.85 \\
\hline P6.11 & 3.32 & 3.01 & 3.32 & 3.10 & 4.42 & 2.55 & 0.13 & 0.35 \\
\hline P6.12 & 3.04 & 3.20 & 2.79 & 3.13 & 4.65 & 3.02 & 0.00 & 0.00 \\
\hline & $N=93$ & & $N=53(58,2 \%)$ & & $N=33(36,3 \%)$ & & $N=5(5,5 \%)$ & \\
\hline P40.1 & 2.41 & 2.88 & 0.81 & 1.37 & 3.61 & 2.15 & 9.8 & 0.45 \\
\hline P40.2 & 2.35 & 2.64 & 0.79 & 1.34 & 3.88 & 1.78 & 9.00 & 1.73 \\
\hline $\mathrm{P} 40.3$ & 1.60 & 2.24 & 0.15 & 0.46 & 4.12 & 1.80 & 1.00 & 2.24 \\
\hline P40.4 & 1.77 & 2.66 & 0.17 & 0.51 & 4.61 & 2.62 & 0.20 & 0.45 \\
\hline P40.5 & 5.69 & 3.32 & 6.49 & 3.59 & 4.70 & 2.31 & 3.60 & 4.16 \\
\hline P40.6 & 5.97 & 3.17 & 6.79 & 3.35 & 4.91 & 2.38 & 4.60 & 4.45 \\
\hline P40.7 & 6.33 & 3.35 & 7.47 & 3.24 & 5.09 & 2.69 & 3.00 & 4.24 \\
\hline P40.8 & 7.22 & 3.15 & 8.26 & 2.78 & 5.82 & 2.88 & 5.40 & 5.08 \\
\hline P40.9 & 8.12 & 2.85 & 8.75 & 2.52 & 7.15 & 2.98 & 7.40 & 4.34 \\
\hline P40.10 & 3.40 & 3.02 & 2.94 & 3.23 & 4.61 & 2.32 & 1.60 & 2.61 \\
\hline P40.11 & 3.91 & 3.28 & 3.47 & 3.41 & 4.97 & 2.90 & 3.20 & 2.95 \\
\hline P40.12 & 6.30 & 4.01 & 5.91 & 4.08 & 7.30 & 3.64 & 5.40 & 5.08 \\
\hline
\end{tabular}

